\title{
The Conflicts of Responsibility for Administrative Personnel in Governmental Information Disclosure and Its Solutions
}

\author{
Siying $\mathrm{Wu}$ \\ School of Public Administration \\ University of Electronic Science and Technology of China \\ Chengdu, China 611731
}

\author{
Zhen Zhang \\ School of Public Administration \\ University of Electronic Science and Technology of China \\ Chengdu, China 611731
}

\author{
Siqi Tian \\ School of Public Administration \\ University of Electronic Science and Technology of China \\ Chengdu, China 611731
}

\begin{abstract}
From the ethical point of view, this paper analyzes the administrative personnel's responsibility conflicts in government information disclosure from three aspects: role conflict, power conflict and interest conflict. Based on this, the corresponding countermeasures are put forward: first, to strengthen the moral construction of administrative personnel and establish a formal mechanism of moral self-discipline; second, to strengthen the design of administrative organizations; third, to promote the ethical values of big data.
\end{abstract}

Keywords-information disclosure; privacy protection; administrative personnel

\section{INTRODUCTION}

As the value norm of public administration, administrative ethics is built on the unity of responsibility, power and interest. The system of administrative conduct and norms is centered on the relationship between individuals, organizations and society [1]. As a kind of normative administrative ethics research, it always has some kind of orderly value appeal, such as "efficiency first", "public welfare first", and "absolute loyalty to superiors and absolute compliance with the law". However, in real life, these values are often mutually exclusive and incompatible in a particular situation of coexistence, and various obligations are often contradictory. Responsibilities at all levels often conflict with each other, leading to a dilemma for executives.

Government information disclosure refers to the active or passive disclosure of information on the interests of social members by the administrative subject according to legal procedures. It also allows information behavior of the public to make full use of the government and system to grasp information by means of inquiry, reading, copying, extracting, listening, viewing and downloading [2]. The government, as the holder and provider of information, on the one hand needs to publish information; on the other hand, it needs to protect secrets based on national interests, trade secrets and personal privacy protection. Therefore, this constitutes the responsibility conflicts of administrative personnel in the government information disclosure.

With the help of the famous foreign scholar Terry Cooper's theory of administrative responsibility, this paper interprets the administrative personnel's responsibility conflicts in the government information disclosure, and attaches importance to the important role of value rationality in the public administrative organization, aiming to provide a new perspective for the study of government information disclosure from the perspective of administrative ethics. We should realize the responsibility of the government and establish an open, transparent and innovative service-oriented government.

\section{ADMINISTRATIVE PERSONNEL's RESPONSIBILITY CONFLICTS IN INFORMATION DISCLOSURE}

According to statistics from relevant departments, only 20 of the more than 80 information resources held by Chinese government departments are open. The way to perfect the government information disclosure can be both legal and ethical. The administrative discretion limits and the standard of citizens' orderly political participation are highly subjective, and the ethical requirements are high, so the conflicts of responsibilities faced by the administrative personnel in the information disclosure need more help from Cooper's administration responsibility theory. It analyzes it from three aspects, power conflict, role conflict and interest conflict.

\section{A. Role Conflict}

Role conflict is caused by major and objective responsibilities. The former is the conflict between the role of administrators as citizens and the role of civil employees, while the latter is the conflict formed by the different roles of administrators in the administrative organization.

The external role conflict is mainly manifested in the external administrative field, and the status of administrative 
personnel has undergone dualistic changes - citizens and civil employees. As citizens, we enjoy the basic rights, the right to know and right of privacy, and should protect the personal information of administrators. As civil employees, the personal information of administrators involves the work of government departments, and is closely related to public interests, and has the obligation to publish his/her activities to the whole society according to the law. China has not yet introduced a special information disclosure system for civil servants. A small number of administrators, especially grass-roots and nonleadership officers, have a resistance to the disclosure of personal information and think that it is not necessary to publish their own information to the public. If the public power in the hands of the administrator is clothed with the right of privacy, protected by law and not supervised publicly, it is likely to become a tool for the administrator to seek private interests, which is not conducive to the self-restraint of the administrator, nor to the exercise of the public supervision power, and is not conducive to improving the credibility of the government.

Internal conflicts are mainly manifested in the internal administration field. On the one hand, administrators must obey the Constitution, laws and superiors; on the other hand, administrators must submit to citizens. Influenced by the idea of "official standard", our government has long been under the influence of the environment of "only obeying the superior, not submitting to the lower classes nor the reality", and naturally ignores the interests of citizens. Between government departments, each department only knows the government information of their department, but know too little about the government information of other departments. In the formulation of information disclosure policy, each department is set in their department, resulting in excessive discretion of the administrative department. The information disclosure standards of different departments are inconsistent, and they argue with each other. The way of information disclosure is standing on the official position, rather than put people first. It prominently highlights their publicity and display obligations. In the long run, citizens' right to know cannot be guaranteed, information disclosure can easily become empty talk, and "sunshine" is cast a shadow.

\section{B. Power Conflict}

The power conflict is the conflict between two or among more objective responsibilities. In the process of work, administrative personnel should not only play multiple roles and shoulder multiple responsibilities, but also be responsible to higher levels, law and the public. Due to the absence of policies and laws, there is a contradiction between the exclusion and incompatibility between the executive acting in accordance with the law and acting according to the will of his superiors.

From the legal point of view, although China's "Regulations on the Opening of Government Information" put forward the disclosure principle of information, but it is no exception; besides the confidential information stipulated by law, all other information needs to be disclosed [3]. However, the regulation does not specifically answer the question of which government information should be disclosed, and its practicality is not strong. The promotion of government information disclosure does not depend on the law, but depends on the degree of "consciousness" of the government. Obviously, such behavior without legal restraint and guarantee must be an anomie. Due to the lack of specific operation rules and system guarantee, the development of information disclosure by the Chinese government is extremely uneven. Moreover, the content of government information disclosure is unsatisfactory for citizens, and the disclosure of information is mainly limited to the disclosure of the service system. Most of the information it discloses is information that citizens know, and its value and applicability are very small. Especially, the Red, Yellow and Blue Kindergarten Incident happened. The public only know the outcome, but don't know the trial process, leading to online questioning one after another. It seems to cast a shadow on the bright badge.

From the organizational point of view, the higher administrative organizations have a large number of decisionmaking information, while the lower administrative organizations know little about decision-making information and may not understand the policy accurately, so the lower administrative organizations have a wide understanding of the actual information disclosure process. Superior administrative organizations cannot supervise and control subordinate administrative organizations in time. When implementing policies at all levels, information disclosure is not standardized As an administrator, on the one hand, he has the obligation to disclose information to citizens, but also has the responsibility to protect the privacy security of citizens. On the other hand, when the administrative unit collects and stores personal data for use and disclosure, it may improperly or intentionally damage the privacy of citizens. In the actual process of government's social management, citizens are often required to provide a large number of personal data, but citizens themselves do not know whether it is reasonable for government departments to collect these personal data. Relevant government departments also have difficulty responsibly making appropriate privacy commitments; however, when government departments use and access personal data, they often do not have the authority and permission of citizens. They may illegally disclose private personal files, medical history, marital history, personal credit rating and other privacy [4]. These also violate the requirements of citizens' protection of personal privacy, which is not conducive to improving the credibility of the government.

\section{Interest Conflict}

Conflict of interest means the occurrence of the conflicts between private interest and public responsibility represented by public officials that administrative personnel do not take corresponding measures interfered by private interests in the process of public administration, making value judgment and policy orientation deviate from the requirements of public interests [5]. Essentially the conflict between government information disclosure and citizen privacy protection is the conflict between personal interests and public interests.

From the perspective of internal cost, government agencies, as the main producers, possessors and managers of 
government information, not only have natural information advantages. In addition, they also make use of their special status and technical advantages to grasp the vast majority of the information resources of the whole society in their own hands. Although government information disclosure is beneficial to citizens, it can provide a basis for citizen to supervise the government. But for the government departments themselves, the active disclosure of government information may lead to loss of interests, weakening of power, withdrawal from the system reform and other adverse consequences. The more information the government discloses, the more transparent the administration, and the more participants in social management, the higher the decision-making cost of government "unanimity". Faced with many possible costs, in order to avoid large investment in human, material, financial, time and energy, and to reduce the risk of social management, the government tends to use various means to minimize or reduce the amount and scope of information disclosure. Subjectively they avoid information disclosure or don't disclose information.

From the perspective of external interests, administrative personnel, as "economic man" individuals, have personal and private interests. Under the circumstance of imperfect information disclosure system, some local governments use power and information to obtain private interests. Power rentseeking and information rent-seeking are very common, such as Kweichow Moutai Incident, the recruitment and change of civil servants in Shanxi, and the collapse of the "8.13" Dixi Bridge in Fenghuang County, Hunan Province. In terms of external supervision, due to the publicity of government information, according to the public goods theory, citizens have a strong demand for government information disclosure. However, due to the integration of information search, it also faces the problem of "free riding". Because once government information is made public, others can get it for free, and those who try to gather it can't enjoy the benefits of it alone. This makes citizens lack enthusiasm for collecting government information, resulting in "rational ignorance". The failure of external supervision and the imperfection of internal supervision have reduced the cost of obtaining private interests for administrators, which is not only the reason why the government is unwilling to disclose information, but also an important source of personal corruption.

\section{SOLUTIONS TO THE DILEMMA OF INFORMATION DiSClOSURE AND PRIVACY PROTECTION}

\section{A. Strengthening the Moral Construction of the \\ Administrative Personnel and Establishing the Moral Self- discipline Mechanism of the Officials}

The individual administrator should strengthen the consciousness of public servant, carry out the open work of Party affairs, establish the value orientation of "responsibility", "honesty", "service", "honest and diligent administration" and "fairness and justice", transform the moral norms into the moral beliefs, and emphasize the concept of professional responsibility and responsibility. Administrative organizations should strengthen the education of administrative ethics and cultivate moral autonomy and self-responsibility of administrative personnel, so that administrative personnel can become a person with moral pursuit and moral responsibility.

Establish the mechanism of moral self-discipline for officials, strengthen ideological education leading, and set up honesty examination records. Once find clues to violations of discipline and law, transfer them to the discipline inspection and supervision organs according to regulations, jointly conduct mass appeals and follow-up questioning activities on government micro-blogs and government affairs accounts, and make administrators achieve the unity of subjectivity and objectivity and the unity of self-discipline and heteronomy in behaving process through internal control and external control.

\section{B. To Strengthen Administrative Organization Design}

First, establish a unified national government data open platform and establish an authoritative and credible information disclosure system. Departments should reach an inter-departmental agreement to unify privacy protection specification [6]. Inter-departmental cooperation in privacy protection can prevent the emergence of privacy issues to a certain extent through technical cooperation and management linking. The common benefits brought by cooperation can reduce the status quo of multiple policies and different orders from different departments. Multi-departmental participation is also conducive to improving the ability of administrative organizations to deal with privacy issues, and then from the overall perspective, improve the level of privacy protection in China.

Second, establish ethical accountability supervision institutions. Establish a set of unified and statutory standards for data and information exchange, form a standardized data and information format, and the administrative personnel shall be accountable for their work by the ethical accountability regulator. The administrative organs holding personal information shall consciously accept the supervision of people and other interested parties and voluntarily declare their "nonaction" to the higher government for reward. Establish citizen supervision and relief system. Citizens can get feedback and legal aid if they find that personal data is illegally revealed or used.

Third, formulate laws and regulations to improve the overall planning and related policies of government information disclosure. Formulate "the government information disclosure strategy" and clarify the requirements for government information disclosure, so as to provide policy support for government data opening work to departments at all levels, and speed up the top-level design of government data opening and the implementation of supporting measures.

\section{To Promote the Ethical Values of Big Data}

First, establish ethical norms and guide social thinking. The government should take root in the traditional ethical soil, combine with the core values of socialism, and form ethical norms with Chinese characteristics. By establishing a high sense of responsibility, administrators should realize the importance of their own actions and establish strict boundaries between information disclosure and privacy protection to really do practical things for the people. 
Second, improve citizens' cognitive ability, give full play to the guiding role of news media in social morality, regularly reward effective information transmission behavior, properly handle invalid information, avoid disrupting the dissemination of effective information by avoid excessive spread of invalid information. So, citizens can truly benefit in the information age. Establish citizen's awareness of privacy protection and improve their ability of information discrimination, which is also conducive to promoting the interaction mechanism between the government and the people.

Third, formulate reasonable network ethics. Under the guidance of the government, society, schools, enterprises and families jointly implement network ethics education, and formulate reasonable network ethics. Promote the positive energy of society, guide the correct development of the media, and promote the structure of social public opinion, which is conducive to the construction of a wise government, making the attitude of the government and the people tend to be equal, public opinion supervision, and democratic politics.

\section{CONCLUSION}

Government information disclosure is an important way to protect citizens' right to know, promote democratic politics and improve the modernization of government governance. It is an unavoidable requirement to establish a responsible government, a transparent government, a service-oriented government and a government ruled by law.

Under the multi-role conflict, administrative personnel should bear in mind that public opinion and public interest are the highest moral principles of public administration, and use this spiritual concept to overcome various narrow value orientations. To resolve the responsibility conflict of the administrator in the government information disclosure lies in realizing the unification of the administrator's subjectivity and objectivity, virtue and merit, self-discipline and heteronomy through the reasonable internal and external control of the government, so as to achieve the good effect of "principalagent".

\section{REFERENCES}

[1] Zhang Kangzhi. Administrative Ethics (Revised Edition). The Open University of China Press, 2005.

[2] Song Chao. Government Information Disclosure and Personnel Privacy Protection. Ethics and Reform, 2015.

[3] Cui Xueli. The Interest Balance between Government Information Disclosure and Secret Protection. Jiangxi Social Sciences, 2014, 34 (07): 167-172.

[4] Liu Dongye. Analysis of Personal Privacy Security in the Age of Big Data. Computer Programming Skills and Maintenance, 2015, (16): 9394.

[5] Liu Bo. Conflict and Balance between Government Information Disclosure and Personal Privacy. Xiangtan University, 2014.

[6] Wu Fenlan. Government Information Disclosure and Personal Privacy Protection. Modern Commerce and Industry, 2010, 22 (05): 274-276. 